\title{
The oxidative degradation by pyrolusite of p-nitrophenol wastewater after micro-electrolysis pretreatment
}

\author{
Shuchuan Peng*, Lili Zhao, Xixi Liu, Dong Chen \\ School of Resources and Environmental Engineering, Hefei University of Technology, CHINA \\ *Corresponding Author: e-mail: scpeng@vip.sina.com, Tel +80-0551-2903990, Fax.+80-0551-2901649
}

\begin{abstract}
P-nitrophenol wastewater was pretreated with iron-carbon micro-electrolysis (ME) technology. After the pretreatment, pnitrophenol was degraded into $\mathrm{p}$-aminophenol. The degradation ratio of $\mathrm{p}$-nitrophenol could almost be up to $95 \%$ when $\mathrm{pH}$ value reached 2.0 and the quantity of added iron scrape was $2.0 \mathrm{~g} / 100 \mathrm{~mL}$. Through the experimental investigation, to identify the changes closely associated with treatment effect on wastewater containing nitrophenol, reaction time, $\mathrm{pH}$, amount, particle size of pyrolusite and shaking speed were analzed. The p-nitrophenol were almost eliminated at a $\mathrm{pH}$ value of 3.5, shaking rate of $150 \mathrm{rpm}$, reaction time of $2 \mathrm{~h}$ and pyrolusite amount of $1.0 \mathrm{~g} / 100 \mathrm{~mL}$, mineral grain size of $75-106 \mu \mathrm{m}$. The removal ratio of COD is over $95 \%$ and TOC has been reduced by $89.0 \%$ at the same time. P-aminophenol was degraded into $\mathrm{H}_{2} \mathrm{O}$ and $\mathrm{CO}_{2}$ finally. The degradation mechanism of wastewater from pretreatment by pyrolusite has been further investigated based on previous work.
\end{abstract}

Keywords: p-nitrophenol; micro-electrolysis; pyrolusite; degrading mechanism

\section{Introduction}

As one typical organic intermediate, nitrophenol is widely used in fine chemicals related to pesticides, pharmaceuticals, dyes. Waste water contains nitrophenol which has great chemical and biological stability, so the degradation is difficult (Tang et al., 2003; Yu et al., 2009; Shan et al., 2010). In the production of p-nitrophenol, p-nitrochloro benzene hydrolysis is used. Except for p-nitrochlorophenol, the wastewater contains small amount of nitro-chlorobenzene, nitrobenzene and a lot of sodium chloride (Yang et al., 2000). As the nitrobenzene compounds and phenolic compounds have strong toxicity and the wastewater has high acidity and salinity (Tang et al , 2009), it is difficult to treat with conventional sewage treatment methods. In this paper, iron-carbon ME technology (Peng et al., 2008) is used as a pretreatment for wastewater, p-nitrophenol as a typical pollutant is converted into p-aminophenol firstly. Then, Oxidation degradation of p-aminophenol is realized by the utilization of pyrolusite (Chen et al., 2008; Lu et al., 2000; Li et al., 2003; Chen et al., 2003). Through the experimental investigation, to identify the changes closely associated with treatment effect on wastewater containing nitrophenol, we analyzed reaction time, $\mathrm{pH}$, amount and particle size of pyrolusite, shaking speed. Theoretical basis has been provided for the application of technics in the oxidative degradation of wastewater containing nitrophenol.

\section{Experimental Materials and Methods}

2.1 Materials: Wastewater was obtained from the p-nitrophenol solution. The wastewater shows a $\mathrm{pH}$ of 5.5 and COD of $1450 \mathrm{mg} / \mathrm{L}$. It has a high level of toxicity, and can not be treated in biochemical method. Besides, the solution has a yellow color, but becomes colorless under acidic condition.

Carbon powder was collected from commercial coke powders over 40 mesh sieve. Waste iron chips were obtained from metal machining workshop mill in Hefei University of Technology. Scrap iron chips were firstly degreased. Before the experiment, and then soaked scrap iron should be activated for $20 \mathrm{~min}$ with in a dilute hydrochloric acid $(1 \mathrm{~mol} / \mathrm{L})$ solution. The product would be cleaned with by distilled water finally.

Pyrolusite used is derived from the manganese mine in Tongling, Anhui. The content of $\mathrm{MnO}_{2}$ in the pyrolusite is $75 \%$. The raw mineral has been screened according to different grain size after it has been smashed. The particles range from 40-200 mesh. 
2.2 Experimental Methods: Treatment of wastewater containing nitrophenol with iron-carbon micro-electrolysis method

$1000 \mathrm{~mL}$ wastewater (contains $1000 \mathrm{~mL} / \mathrm{L}$ nitrophenol) was firstly added in the conical flask. After that, iron chips, carbon powder were added to $2.0 \mathrm{~g} / 100 \mathrm{~mL}$ and $1.0 \mathrm{~g} / 100 \mathrm{~mL}$ respectively. $\mathrm{pH}$ value of the solution could be adjusted to around 2.0 . Then the solution would be shaken at a speed of $150 \mathrm{r} / \mathrm{min}$ in room temperature condition for $3 \mathrm{~h}$. The supernatant of solution is obtained after centrifugation. The residual concentration of nitro-phenol is measured with spectrophotometry. The conversion ratio of nitrophenol and $\mathrm{COD}_{\mathrm{Cr}}$ were measured by potassium-dichromate method.

2.3 Procedure: Oxidation reaction was performed firstly at $25^{\circ} \mathrm{C}$ with a pyrolusite dosage of $1 \mathrm{~g} / 100 \mathrm{~mL}(<380 \mu \mathrm{m}) . \mathrm{pH}$ value of solution was adjusted to around 3.0. The supernatant solution was obtained at different time during reaction. Different amounts of manganese complex were involved in $100 \mathrm{~mL}$ micro-electrolysis water at a $\mathrm{pH}$ value of around 3.5 , and the reaction lasted $2 \mathrm{~h}$ to analyze the influence of pyrolusite dosage. The influence of particle size on treatment effect was also investigated. $1 \mathrm{~g}$ particles with the sizes of more than $380 \mu \mathrm{m}, 180-380 \mu \mathrm{m}, 106-180 \mu \mathrm{m}, 75-106 \mu \mathrm{m}$ and less than $75 \mu \mathrm{m}$ were dropped in $100 \mathrm{~mL}$ microelectrolysis water respectively.

The total organic carbon test conditions were as follows: the sizes of $0.5 \mathrm{~g}$ pyrolusite particles were selected in the range of $75 \mu \mathrm{m}$ to $106 \mu \mathrm{m}$ and applied into $50 \mathrm{~mL}$ micro-electrolysis water, $\mathrm{pH}$ was adjusted at 3.5 , shaking speed was $150 \mathrm{rpm}$ at room temperature. The $\mathrm{COD}_{\mathrm{Cr}}$ and total organic carbon value would be measured at the reaction time of $0,0.5,1,2 \mathrm{~h}$ after the reaction began respectively.

2.4 Analysis methods: $\mathrm{COD}_{\mathrm{Cr}}$, Total organic carbon (TOC) and concentration of p-nitrophenol were analyzed referring to the standard methods(Clesceri et al, 1998). The $\mathrm{pH}$ value of the solution in this research work is measured with PHS-3B precision pH meter, produced by the U.S. Mettler Corporation. Conversion of nitrophenol is measured according to the following formula:

$$
\eta=\left(\mathrm{C}_{0}-\mathrm{C}_{\mathrm{e}}\right) / \mathrm{C}_{0} \times 100 \%
$$

In this expression,

$\eta \quad$ Conversion(\%).

$\mathrm{C}_{0} \quad$ Initial concentration of nitrophenol (mg/L).

Ce Residual concentration $(\mathrm{mg} / \mathrm{L})$.

\section{Results and discussion}

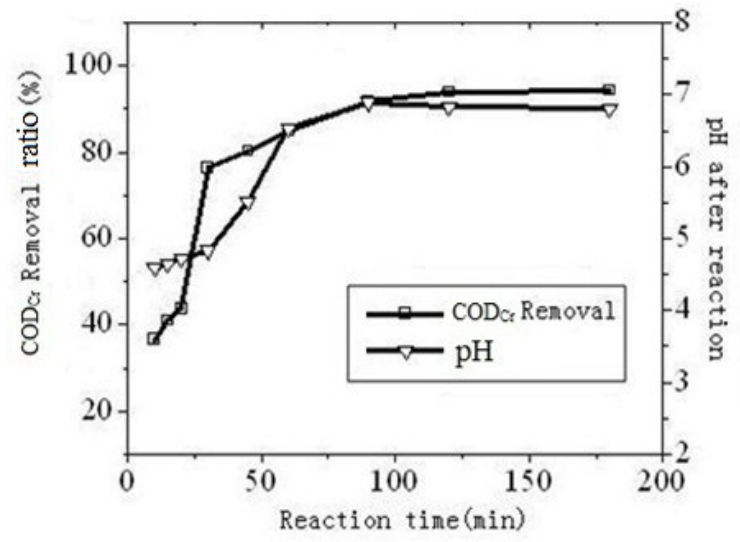

Figure 1. Influence of oxidation time on treatment effect

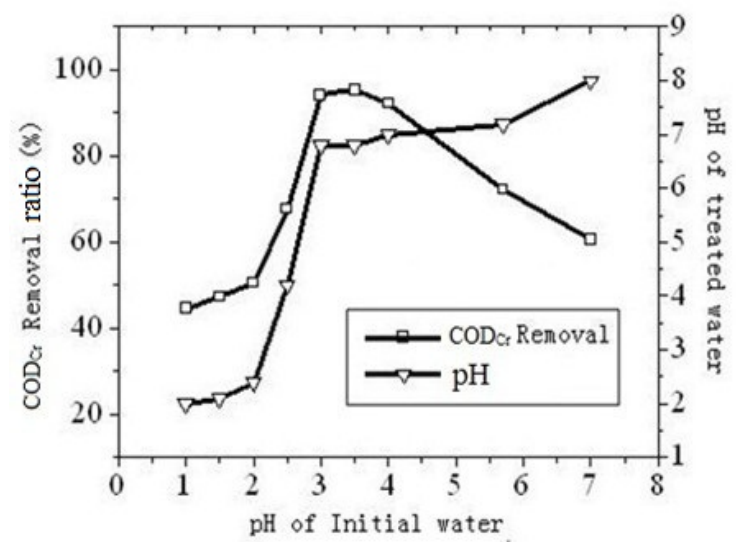

Figure 2. Influence of $\mathrm{pH}$ on treatment effect

3.1 The effect of oxidation reaction time: The results after pretreatment of ME showed a p-nitrophenol conversion of $97.9 \%, 21 \mathrm{mg} / \mathrm{L}$ for $\mathrm{p}$ nitrophenol concentration and $1216 \mathrm{mg} / \mathrm{L}$ for $\mathrm{COD}_{\mathrm{Cr}}$.

The results of oxidation were shown in Figure 1. According to the Figure, the reaction rate is very fast during the first $60 \mathrm{~min}$ and the $\mathrm{pH}$ of the solution changes fast accordingly. After that period, the reaction rate is slow and becomes especially slow after $90 \mathrm{~min}$. The removal ratio of $\mathrm{COD}_{\mathrm{Cr}}$ is $94 \%$ and $\mathrm{pH}$ value is 6.8 after $120 \mathrm{~min}$. More reaction time can't contribute to any changes in $\mathrm{COD}$ and $\mathrm{pH}$ value. So $2 \mathrm{~h}$ are enough for the reaction.

3.2 Influence of $\mathrm{pH}$ on the oxidation treatment of wastewater: When the pyrolusite dosage reached $1 \mathrm{~g} / 100 \mathrm{~mL}$ and after $2 \mathrm{~h}$ reaction, oxidation effects of water output at different $\mathrm{pH}$ values were depicted in Figure 2 . It showed that $\mathrm{pH}$ value played an important role in oxidation of organic matter by manganese complex. When the $\mathrm{pH}$ of the wastewater was between 3 to 4 , the degradation ratio of wastewater to $\mathrm{COD}_{\mathrm{Cr}}$ reached above $90 \%$. However, if the $\mathrm{pH}$ range was less than 3 or more than 4 , the degradation ratio dropped dramatically. This might be caused by a large number of iron ions in solution which had been pretreated 
by ME. The removal of organic matter could not be singlely attributed to manganese complex, but the combined effect of iron ions and manganese complex. In the reaction progression, the increase of $\mathrm{pH}$ value was another result. If the $\mathrm{pH}$ value was between 3 and 4 before reaction, it would be transformed into 6.8 to 7.0 after reaction. In this process, partly organic matter in the reaction system was removed because of the flocculation effect of $\mathrm{Fe}(\mathrm{OH})_{3}$. So the removal ratio of $\mathrm{COD}_{\mathrm{Cr}}$ was high and $\mathrm{pH}$ value was adjusted to 3.5 in experiment.

3.3 Influence of pyrolusite dosage: It could be observed from Figure 3 that, when the dosage of pyrolusite is $0.5 \mathrm{~g} / 100 \mathrm{~mL}$, the treatment had little effects. The dosage was not enough to oxidize the pollutants in the water. If the dosage is $1.0 \mathrm{~g} / 100 \mathrm{~mL}$, the removal ratio can reach $94 \%$. More dosage cannot make too much difference, so $1.0 \mathrm{~g} / 100 \mathrm{~mL}$ is selected in the experiment.

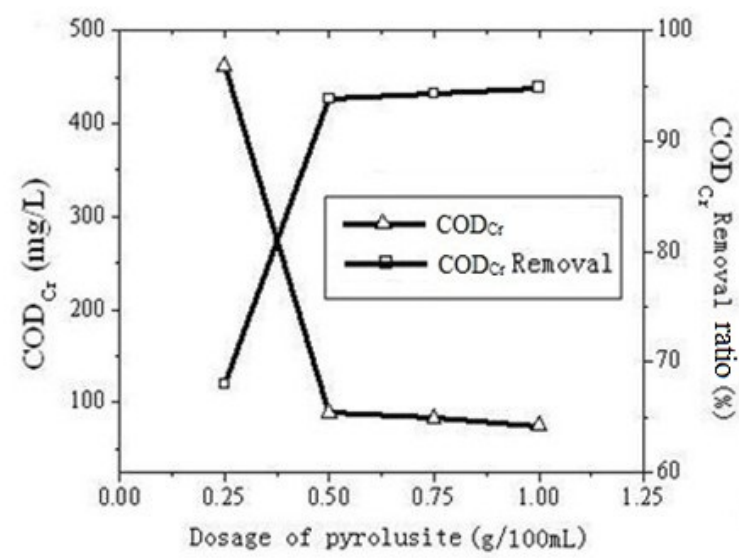

Figure 3. Influence of dosage on treatment effect

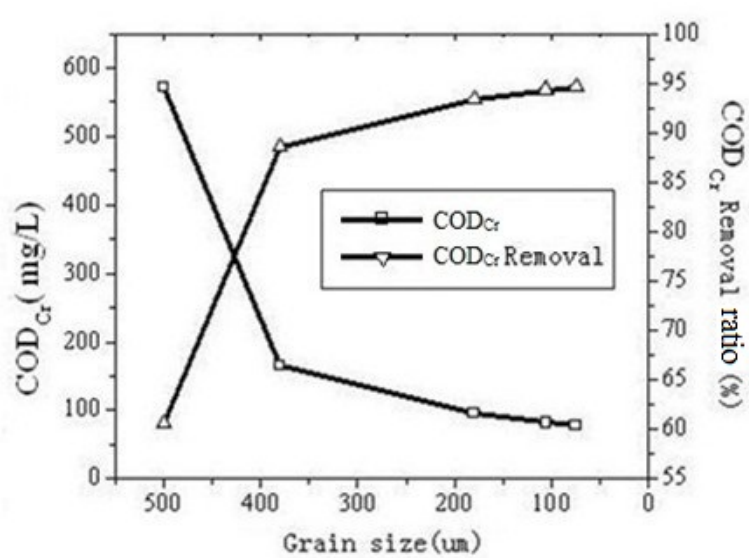

Figure 4. Influence of granularity on treatment effect

3.4 Influence of particle size: It suggests a larger particle size could cause a low removal ratio of $\mathrm{COD}_{\mathrm{Cr}}$, which is just $60 \%$ in Figure 4. The higher removal ratio could be gained as the particle size becomes smaller, because the decrease of particle size contributed to the increase of specific surface area. It would have more surface active sites when the specific surface area was observed larger, so it would be easier for the oxidation-reduction reaction to take place. In the experiment, particles with the size of $75-106 \mu \mathrm{m}$ was chosen.

3.5 Influence of shaking speed: Pyrolusite particles with different sizes between $75 \mu \mathrm{m}$ to $106 \mu \mathrm{m}$ were added into $100 \mathrm{~mL}$ copper sulfate supernatant water at a $\mathrm{pH}$ of 3.5. The reaction lasted $2 \mathrm{~h}$ before obtaining supernatant water for measuring $\mathrm{COD}_{\mathrm{Cr}}$. The influence of shaking speed on treatment effect is shown in Figure 5. It can be seen that shaking speed has a significant effect on the treatment of wastewater by manganese complex. The reaction can take place when it is static, but the removal ratio is just $40 \%$. As the shaking speed grew, the COD removal would be improved. It is attributed to degradation occurring on the surface of the mineral.

Faster shaking rate led to the increase of surface contact probability of pollutants and minerals. However, when the shaking speed was around 150rpm or more, the removal ratio achieved a constant, so the rate of $150 \mathrm{rpm}$ was chosen as an optimal speed.

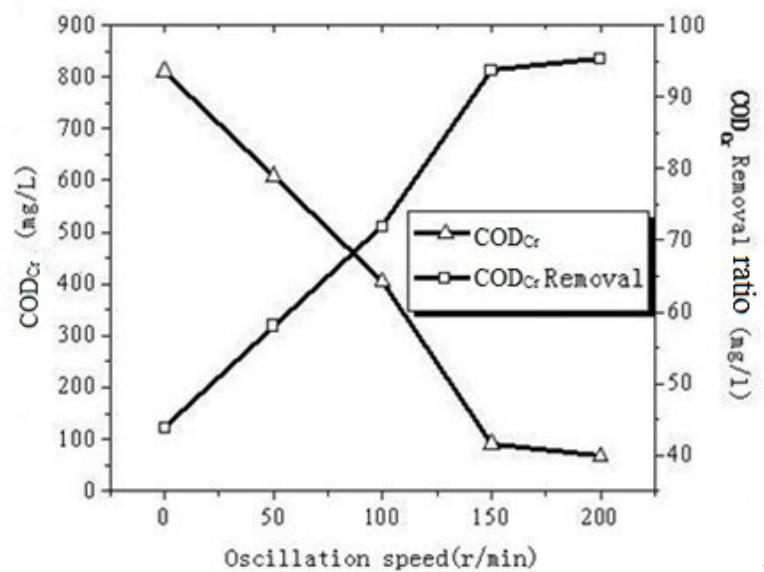

Figure 5. Influence of shaking speed treatment effect

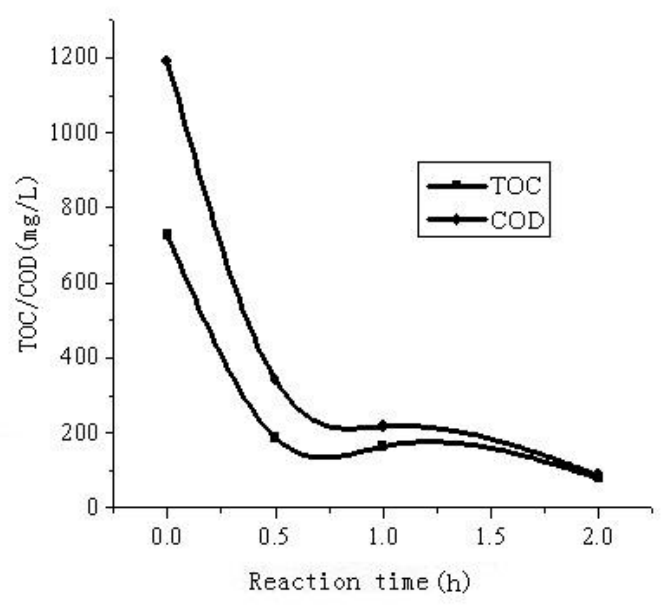

Figure 6. The change of $\mathrm{TOC}$ and $\mathrm{COD}_{\mathrm{Cr}}$ with reaction time 
3.6 Changes of total organic carbon in reaction: As the wastewater is composed of many complex compositions, but the quantity is not large. Besides carbon dioxide, the main content of compositions was carbohydrate. It was difficult to describe the content of every composition, but total organic carbon can be used to evaluate the oxidation degree of wastewater by micro-electrolysis pyrolusite oxidative degradation, so minerization degree of p-nitrophenol can be studied. The experimental results in Figure 6 suggested that TOC in wastewater show a less content as the time went on. 0.5 hour later, TOC decreased by $74.2 \%$. $2 \mathrm{~h}$ later, TOC was reduced by $89.0 \%$, which meant that $89.0 \%$ of the organic matters had been converted into carbon dioxide. About $11.0 \%$ organic matters still remained in the solution. The value of $\mathrm{COD}_{\mathrm{Cr}}$ was more than that of TOC. It is possibly explained as the value of $\mathrm{COD}_{\mathrm{Cr}}$ consisted of chemical oxygen demand not only required by organic matters, also by inorganic nitrogen, iron and manganese ions in the solution.

\section{Reaction mechanism}

UV spectra before and after the micro-electrolysis reaction of wastewater are shown in Figure 7(a). A characteristic absorbance peak for nitrophenol at $318 \mathrm{~nm}$ dispeared after ME treatment, and three absorption peaks at $225 \mathrm{~nm}, 275 \mathrm{~nm}$ and $300 \mathrm{~nm}$ appeared. However after acidification, the absorption peak at $300 \mathrm{~nm}$ disappears, the absorption peak at $225 \mathrm{~nm}$ shifts to $220 \mathrm{~nm}$. Because $220 \mathrm{~nm}$ and $275 \mathrm{~nm}$ belong to the absorption peaks of p-aminophenol (Yan, 1995). It can be p-nitrophenol has been reduced to paminophenol through iron-carbon reaction.

UV absorption spectra of wastewater by micro-electrolysis and pyrolusite oxidative degradation are shown in Figure 7(b). If the solution had been treated by manganese complex for $5 \mathrm{~min}$, the UV curve of the solution was generally the same as that of the solution after micro-electrolysis reaction. The only difference was that the absorption peak intensity became weaker. If the solution had been treated for $15 \mathrm{~min}$ and $30 \mathrm{~min}$, blue-shift occurs and the absorption peak was further weakened. After a period of more than $60 \mathrm{~min}$, a new absorption peak appeared at $245 \mathrm{~nm}$. At the same time, the absorption peaks at $220 \mathrm{~nm}$ and $270 \mathrm{~nm}$ gradually disappeared. After $120 \mathrm{~min}$, more peaks disappeared, only the peak at $245 \mathrm{~nm}$ left, which was ascribed to the oxidation products of aminophenol. In fact, the absorption peaks of phenol-salt, $-\mathrm{NH}_{3}$ and p-benzoquinone were all in the area of $230-256 \mathrm{~nm}$. It has been reported that the absorption peak at $245 \mathrm{~nm}$ corresponds with p-benzoquinone (Willeams, 2001; Zhang et al, 2006), so aminophenol had possible degraded resultants as p-benzoquinone, phenol and inorganic nitrogen through oxidation.
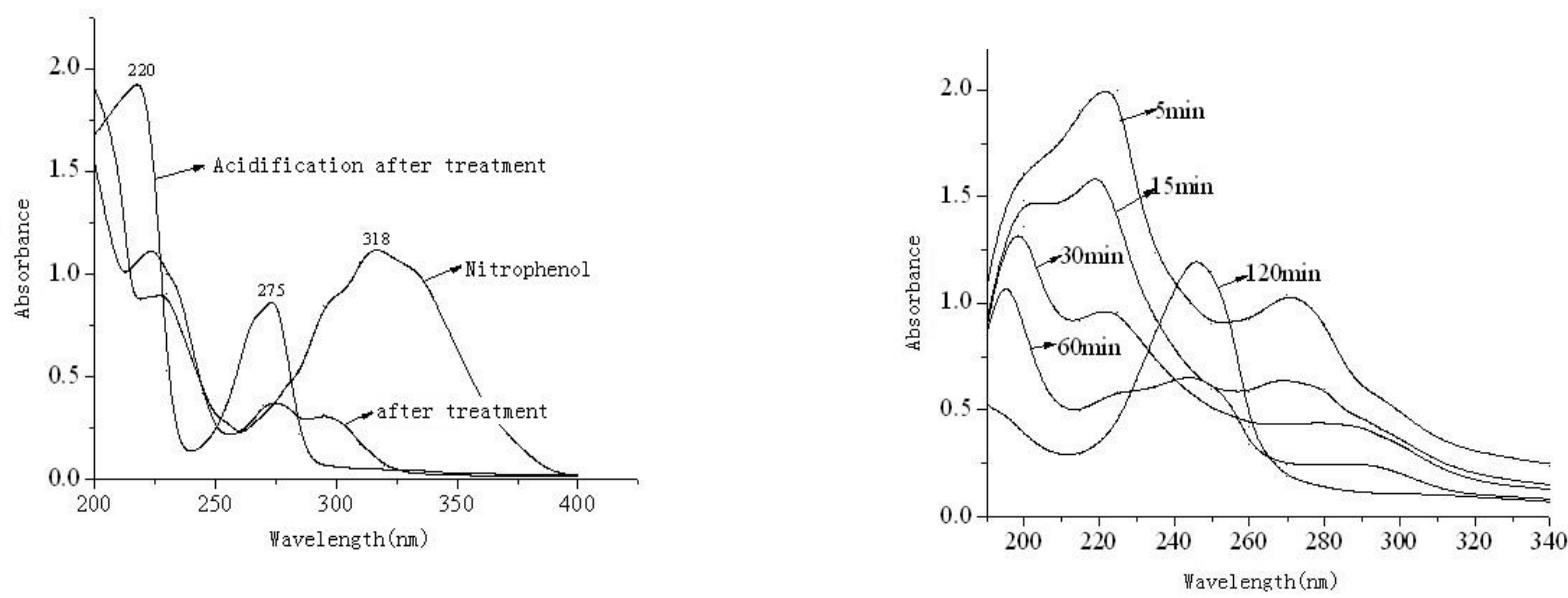

Figure 7. UV spectra of reaction production with micro-electrolysis and pyrolusite

Infrared absorption spectra of sediments after reaction were also analyzed in Figure 7. It was possible that the sediments consisted of organic matters that contain $\mathrm{NH}_{2}{ }^{-}, \mathrm{NH}_{4}{ }^{+}$, aliphatic nitro compounds and benzene, so aminophenol was degraded into small molecule organic matter, inorganic nitrogen, water and carbon dioxide. Because of the coagulation effect of iron Ion and the adsorption effect of manganese complex, part of the organic and inorganic materials had been separated from the solution, so the general degradation process is the combined effect of micro-electrolysis, oxidation degradation, coagulation and adsorption.

According to the previous analysis, degradation mechanism of wastewater by pyrolusite oxidation was the reduction of $\mathrm{p}$ nitrophenol in the wastewater into p-aminophenol by iron-carbon. In acid condition, p-aminophenol was reduced to pbenzoquinone and phenol by pyrolusite oxidative degradation; finally, most contents were oxidized to organic matter, water and carbon dioxide. At the same time, colloid formed by iron ions in the solution and pyrolusite caused precipitations of the small molecules after degradation. 


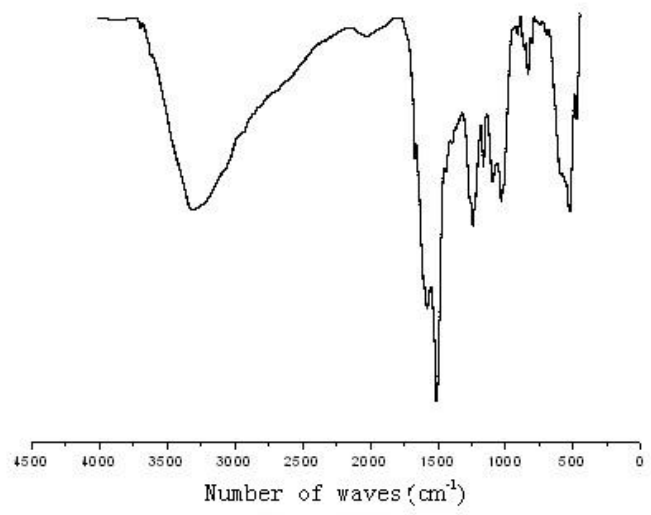

Figure 8. Infrared absorption spectra of the degradation of nitrophenol by micro-electrolysis pyrolusite

\section{Conclusions}

After a batch of experiments, The optimal conditions for the oxidative degradation of nitrophenol wastewater after pretreatment of iron-carbon micro-electrolysis by pyrolusite is determined as follows: $1 \mathrm{~g}$ pyrolusite with the size of $75-106 \mu \mathrm{m}$ for every $100 \mathrm{~mL}$ iron-carbon wastewater, $\mathrm{pH}$ is $3.5,150 \mathrm{rpm}$ at shaking speed. The reaction lasts for $2 \mathrm{~h}$. The degradation ratio of $\mathrm{p}$-nitrophenol is generally $100 \%$, removal ratio of CODcr can be $95 \%$ and the total carbon removal ratio reaches $89.0 \%$. It is considered in this paper that the possible products of oxidative degrading organic matter after pretreatment by pyrolusite is: p-aminophenol is oxidized to p-benzoquinone and phenol. Because of the instability of these substances, they are further oxidized to unsaturated organic acids. Finally, most of the organic acids are oxidized to $\mathrm{CO}_{2}$ and $\mathrm{H}_{2} \mathrm{O}$. Amino- is possibly oxidized to $\mathrm{NO}^{-}, \mathrm{N}_{2}$ and so on. Micro-electrolysis reaction is to convert p-nitrophenol into p-aminophenol or other organic matters which are susceptible to oxidation like phenol. The oxidative degradation of nitrophenol wastewater from pretreatment of iron-carbon micro-electrolysis by pyrolusite is a combined effect of oxidative degradation, coagulation and adsorption. Under acid condition, organic matters from pretreatment are oxidative degraded into organic matters of small molecule, $\mathrm{CO}_{2}$ and $\mathrm{H}_{2} \mathrm{O}$. The coagulation effect of ferrichydroxide and sorption make the organic matters of small molecule deposit. he pretreatment of nitrophenol wastewater with ironcarbon micro-electrolysis method has the advantages of less investment, operation cost and convenient operation. P-aminophenol from the pretreatment is degraded with inexpensive pyrolusite. It has a good effect and pushes forward the development of pollution treatment.

\section{Acknowledgements}

This work was supported by National Special Programme on Water Pollution Control and Treatment (Grant No. 2008ZX07316004) and the Key Technologies R\&D Program of Anhui province(Grant No. 08010202140).

\section{References}

Chen C.X. and Lu A.H., 2002. Progress and Prospect in Pollution Control by Natural Minerals. China Non-metallic Mining Industry Herald, Vol. 5, No. 29, pp. 29-33(in Chinese).

Chen T.H. and Wang J.Q., 1993. Treatment of sulfur-containing wastewater by natural manganese catalyzed oxidation. Environmental Science, Vol. 14, No. 4, pp. 58-61(in Chinese).

Clesceri L.S., Greenberg A.E. and Eaton A.D., 1998. Standard methods for the examination of water and wastewater, $20^{\text {th }} . E D$., American Public Health Association, American Water Works Association and Water Environment Federation, United Book Press, Inc., Baltimore Maryland.

Li G.Y., Lu A.H. and Gao X, 2003. An investigation into the oxidation and degradation of phenol in water by natural cryptomelane. Acta Petrologica et Mineralogica, Vol. 22, No. 2, pp. 162-166(in Chinese).

Lu A.H., Lu X.Y., Ren Z.P., Han L.R., Fang Q.F. and Han Y, 2000. Environmental mineralogy studies of natural Fe-Mn oxides and hydroxides. Earth Science Frontiers, Vol. 7, No. 2, pp. 473-482(in Chinese).

Peng S.C., Liu G.D., Xie J.J. and Zhu R, 2008. Treatment of nitrophenol wastewater by iron filings microelectrolysis and a manganese complex. Treatment of Industrial Water, Vol. 28, No. 10 pp. 55-58(in Chinese).

Shan Z.G., Wang J.Q., Lu J., Shen Y.H. and Pan Y, 2010. Kinetics study on the treatment of p-nitrophenol wastewater by electrocatalysis oxidation with manganese-doped $\beta-\mathrm{PbO}_{2}$. Industrial Water and Wastewater, Vol. 30, No. 1, pp. 49-52 (in Chinese). 
Tang D.Y., Zheng Z. and Guo Z.B., 2009. Treatment of p-nitrophenol wastewater by adsorption of activated carbon fiber. Chemical Protection, Vol. 29, No. 3, pp. 239 241(in Chinese).

Tang P., Zhou J.T., Wang J. and Liu J, 2003. Research progress of treatment of nitrobenzene wastewater. Industrial Water Treatment, Vol. 23, No. 3, pp. 16 19(in Chinese).

Willeams D.H. and Fleming I., 2001. Spectroscopic methods in organic chemistry. $6^{\text {th }}$ ed. McGraw Hill Higher Education, New York United States, 304p.

Yan Y.L., 1995. Analysis of modern instruments. $2^{\text {nd }}$ ed. China Agriculture University Press. Beijing China, 224p(in Chinese).

Yang B.D., 2000. Discussions on the treatment process of nitrophenol wastewater. Industrial Water and Wastewater, Vol. 31, No. 6, pp. 29-30 (in Chinese).

Yu X.J., She Z.L., Gao M.C. and Li B.S., 2009. Experimental research on the static adsorption of nitrophenol in water by PAC. Industrial Water and Wastewater, Vol. 40, No. 2, pp. 23-26(in Chinese).

Zhang L.Z., Chen Z.L., Ma J. and Yu M., 2006. Study on mechanism of phenol oxidized by fresh manganese dioxide in aqueous. Environmental Science, Vol. 27, No. 5, pp. 941-944 (in Chinese).

\section{Biographical notes}

S. C. Peng received M. S. from Hefei University of Technology, China in 1993. Presently, he is a Professor in the School of Resources and Environmental Engineering, Hefei University of Technology, China. His research interests include Water Pollution Ecological Control and Environmental Mineralogy. He has published more than fifty papers in referred national and international Journals.

L. L. Zhao is postgraduate student in the School of Resources and Environmental Engineering, Hefei University of Technology, China.

X. X. Liu is undergraduate student in the School of Resources and Environmental Engineering, Hefei University of Technology, China.

Dr. D. Chen is a lecturer in the School of Resources and Environmental Engineering, Hefei University of Technology, China. His current area of research includes Environmental Mineralogy and Environmental Materials. He has presented some research articles.

Received January 2010

Accepted May 2010

Final acceptance in revised form September 2010 